\title{
INFRAESTRUTURA E DESENVOLVIMENTO: o que se pode esperar da Ponte Salvador-Itaparica? Bahia-Brasil
}

\author{
Francisco Lima Cruz Teixeira* \\ Sílvio Vanderlei Araújo Sousa**
}

\begin{abstract}
Este artigo objetiva analisar o projeto do Sistema Viário do Oeste (SVO), no qual consta a construção da Ponte Salvador-Itaparica, à luz das discussões sobre a relação entre infraestrutura e crescimento econômico, assim como daquelas que ampliam o foco para incluir questões pertinentes ao desenvolvimento socioambiental. Essa revisão foi utilizada para apreciar o projeto e para analisar as pré-condições econômicas e sociais presentes em quatro Territórios de Identidade que sofrerão mais diretamente seus impactos. A análise dos dados e das informações não permite postular que o projeto do Sistema Viário do Oeste - com a sua ponte - poderá contribuir, de forma significativa, para mitigar o quadro de profunda desigualdade e promover o desenvolvimento endógeno e sustentável dos territórios. A abordagem utilizada nessa análise, ao rejeitar a visão econômica tradicional, amplia a discussão sobre as relações entre investimentos em infraestrutura e desenvolvimento regional, utilizando as evidências deste estudo de caso.
\end{abstract}

PAlAVRAS-chave: Infraestrutura. Desenvolvimento. Territórios de Identidade. Aglomerações Produtivas. Políticas Regionais.

\section{INTRODUÇÃO}

A partir de 2010, o Governo do Estado da Bahia passou a contratar a elaboração de projeto para a construção de uma ponte entre Salvador e a Ilha de Itaparica, atravessando diretamente a Baía de Todos os Santos, com extensão de 12 quilômetros. Essa ponte constitui a parte mais importante do Sistema Viário do Oeste (SVO), pois abre uma nova entrada para a grande península onde se localiza a Região Metropolitana de Salvador (RMS), integrando-a com a BR 242, principal via de acesso ao oeste do estado e do país. Além de melhorar a infraestrutura de transporte, pretende-se que a construção dessa ponte seja parte de um plano de desenvolvimento socioeconômico da Bahia, contribuindo para alavancar o crescimento do Estado por vários anos, por meio de investimentos nos Territórios de Identidade

* Universidade Federal da Bahia (UFBA). Escola de Administração. Núcleo de Pós-Graduação em Administração. Av. Reitor Miguel Calmon, s/n, Vale do Canela. Cep: 40110903. Salvador - Bahia - Brasil. teixeira@ufba.br

** Universidade Federal da Bahia (UFBA). Escola de Administração. Núcleo de Pós-Graduação em Administração.

Av. Reitor Miguel Calmon, s/n, Vale do Canela. Cep: 40110903. Salvador - Bahia - Brasil. suader@gmail.com do Recôncavo, principalmente em sua região sul, e do Baixo Sul. Pretende-se também que o projeto promova o desenvolvimento urbano pela ocupação planejada da Ilha de Itaparica, reduzindo a demanda por espaços habitacionais na região nordeste da RMS. Para isso, são mencionados diversos investimentos complementares em projetos de infraestrutura urbana na Ilha. O projeto da ponte Salvador-Itaparica é discutido desde a década de 1960. A atual iniciativa do governo da Bahia representa um passo adiante na realização dessa ideia. ${ }^{1}$

A relação entre investimentos em infraestrutura e crescimento foi, historicamente, pouco explorada pelos estudos econômicos ortodoxos. Essa lacuna começou a ser preenchida a partir do final da década de 1980, com a publicação do trabalho de Aschauer (1989). A partir desse artigo, vários trabalhos foram publicados para estimar a contribuição do "capital público" ao crescimento, geralmente utilizando funções de produção do tipo Cobb-Douglas. Nesses estudos, são calculadas regressões nas quais a variável dependente é o

${ }^{1}$ Informações do site (http://www.pontesalvadorilhadeitaparica.ba.gov.br/), acesso em 15/06/2016, $10 \mathrm{~h}$. 
volume de produção em uma dada região e as variáveis independentes são capital privado, capital público e trabalho, utilizando-se uma constante para o nível tecnológico. Ao revisar esses trabalhos, Munnel (1992) conclui que, mesmo considerando a necessidade de aprimorar as quantificações, há sólidas evidências de que investimentos em infraestrutura pública provocam significativos retornos em termos de crescimento econômico.

Usando outra abordagem, a Teoria do Desenvolvimento já atribuía um papel crucial à infraestrutura no combate às desigualdades regionais. Tanto Myrdal (1957) como Perroux (1950), por exemplo, consideravam a infraestrutura como um fator de atração de investimentos para uma região, dado que os investimentos privados e públicos possuem natureza complementar. Segundo esses autores, os benefícios da dotação de infraestrutura podem se opor à tendência de perpetuação das disparidades regionais, caso atuem apenas as livres forças de mercado. Para Hirschman (1958), além de atrair investimentos privados, a provisão de infraestrutura é indispensável para a geração de um nível mínimo de urbanização necessária ao desenvolvimento econômico.

Os trabalhos mais recentes sobre o tema defendem que os efeitos positivos dos investi$\infty$ mentos em infraestrutura se dão pelo aumento $\bigodot_{\text {N }}^{\infty}$ da competitividade dos empreendimentos da ๙ região receptora, devido à redução dos custos de produção e distribuição, e pela atração de novas empresas, estimulando o crescimento econômico. Entretanto, os estudos revisados por Munnel (1992) que partem desse pressu$\dot{\sim}$ posto revelam que os impactos sobre o crescimento decrescem à medida que o foco da quantificação se estreita do nível nacional para o regional. A magnitude do impacto pode variar também em função da natureza do projeto e das especificidades da região receptora. Ou seja, não seria possível derivar relações fixas entre investimentos em infraestrutura e seus efeitos no crescimento econômico. Nessa linha, as evidências advindas de um conjunto de projetos da China, avaliados por Ansar et al. (2016), surpreendem pelos parcos resultados por eles alcançados, a despeito das expectativas quanto à sua importância para o crescimento econômico daquele país. Por outro lado, as avaliações de projetos de infraestrutura levam cada vez mais em consideração seus impactos na qualidade de vida da população atingida, além da sustentabilidade ambiental, e não apenas no crescimento econômico, o que implica uma abordagem mais ampla do tema.

Este artigo tem por objetivo analisar os possíveis efeitos da construção do Sistema Viário do Oeste (SVO) e da sua Ponte Salvador-Itaparica nos territórios que sofrerão seus impactos. Para tanto, inicialmente é feita uma breve revisão da literatura sobre a relação entre infraestrutura e desenvolvimento. Em seguida, o projeto do SVO é descrito e analisado, sendo contraposto às visões mais recentes sobre os impactos de projetos de infraestrutura nos territórios que os abrigam. As pré-condições atualmente existentes nesses territórios para potencializar os investimentos são também analisadas, tomando-se variáveis e indicadores econômicos e sociais. Por último, são apresentadas as conclusões do trabalho, com um resumo das críticas feitas ao projeto, principalmente do ponto de vista do desenvolvimento regional, com base em um tipo de análise que parece ser pertinente para avaliar outros investimentos dessa natureza.

\section{INFRAESTRUTURA E DESENVOL- VIMENTO REGIONAL}

A partir do trabalho pioneiro de Aschauer (1989), vários estudos foram realizados com o objetivo de calcular o impacto dos investimentos públicos em infraestrutura no crescimento econômico. Nos trabalhos revisados por Munnel (1992), os autores partem da abordagem tradicional, que utiliza a função de produção do tipo Cobb-Douglas para estimar a contribuição do capital público, nesse caso, 
separado do capital privado na equação, para inferir o aumento da produtividade e da produção. Os efeitos positivos da infraestrutura sobre o crescimento seriam provenientes do próprio investimento com a sua demanda, da atração que ela exerce sobre novos investimentos e do crescimento da produtividade resultante da melhoria das condições de produção na região beneficiada. Além disso, melhorias infraestruturais resultariam em externalidades positivas para todos os agentes. Primeiro, devido ao fato de que a maioria de seus componentes, a exemplo de estradas e pontes, são bens públicos. Ou seja, seu uso por um agente não exclui os outros agentes de seus benefícios. Segundo, investimentos em infraestrutura, a exemplo de sistemas de tratamento de esgotos, podem reduzir externalidades negativas, nesse caso a poluição de mananciais. Terceiro, devido à economia de escalas, os altos custos desses investimentos são distribuídos por um grande número de usuários, reduzindo o seu custo unitário à medida que novos agentes se beneficiam. Por último, os autores consideram que a infraestrutura pública provê as pré-condições básicas para a atividade econômica, constituindo-se em um fator locacional de primeira importância (Eberts, 1990).

Embora Munnel (1992) conclua que os estudos por ela revisados apresentam sólidas evidências com base nas quais é possível afirmar que existe uma correlação positiva entre infraestrutura pública e crescimento, quando os números são agregados em âmbito nacional (EUA), alguns questionamentos sobre esses resultados foram levantados por parte de economistas que utilizam o mesmo referencial. A primeira crítica concentrou-se na metodologia utilizada para estimar o impacto do investimento público no crescimento, uma vez que as séries históricas utilizadas, tanto para o investimento público como para o produto, apresentam as mesmas tendências, levando a correlações que poderiam ser consideradas espúrias. Segundo, as estimativas numéricas do impacto da infraestrutura no crescimento apresentadas pelos diversos trabalhos, são muito diferentes, gerando suspeitas sobre os resultados. Terceiro, para os críticos, a relação de causalidade pode se dar em outra direção: do crescimento para o investimento público e não vice-versa. Segundo Munnel (1992), os críticos estavam preocupados em questionar a pertinência dos argumentos que continuamente advogam o aumento dos investimentos públicos para a sustentação do crescimento, os quais podem estar contaminados por interesses particulares.

Uma crítica mais recente à visão tradicional sobre a relação entre infraestrutura e desenvolvimento se origina da análise do caso da China, país admirado por suas altas taxas de crescimento econômico, o que teria relação, entre outras variáveis, com os altos investimentos em infraestrutura. Ansar et al. (2016), baseados em resultados da análise de 95 projetos de infraestrutura de transportes (rodovias e ferrovias) construídos entre 1984 e 2008 na China, em comparação com os efeitos de um conjunto de 806 projetos de transporte construídos em países democráticos ricos, chegam a conclusões opostas e surpreendentes, que desafiam a visão tradicional. As evidências apresentadas pelos autores mostram que os parcos resultados dos projetos analisados levam a riscos macroeconômicos substanciais, traduzidos em acumulo de dívidas impagáveis, distorção na expansão monetária e perda de oportunidades de investimentos alternativos. Eles chegam a levantar a hipótese, na contramão da maioria dos estudos ortodoxos, de que o superinvestimento em infraestrutura contribui para o baixo desempenho e a instabilidade da economia. O crescimento chinês poderia ser ainda maior caso não houvesse perdas econômicas decorrentes do excessivo número de grandes projetos inviáveis financeiramente que foram iniciados naquele período.

No Brasil, a relação entre infraestrutura e crescimento foi pesquisada por Ferreira (1996), em um momento em que os investimentos públicos apresentavam uma tendência declinante (1976-1993). A partir dos resulta- 
dos quantitativos, em estudo que utiliza a mesma metodologia dos autores norte-americanos (função de produção Cobb-Douglas), o autor conclui que, no Brasil, observa-se uma forte relação entre infraestrutura e produto, no longo prazo. Para Ferreira, a queda nos investimentos públicos durante o período analisado levou a significativa redução do crescimento e se constituía em um forte obstáculo à sua retomada.

Por outro lado, Benitez (1999) procurou estimar a participação e o impacto das infraestruturas no desenvolvimento regional, a partir da relação entre o produto e a produtividade e as diferentes dotações a elas destinadas em cada região do país. Os resultados calculados por Benitez revelam uma alta elasticidade entre a dotação e a produtividade regional. Além disso, o autor propõe que uma melhor dotação aumenta a produtividade e, consequentemente, a competitividade dos investimentos privados. Assim, uma região bem dotada nesse âmbito possui vantagens locacionais em relação a outra sem a mesma dotação, aumentando suas possibilidades de desenvolvimento. Segundo o autor, diferenças na dotação de infraestrutura influem significativamente nas disparidades regionais observadas no país.

Em trabalho mais recente, Domingues, Viana e Oliveira (2007) analisam o possível im$\infty$ pacto de um conjunto de projetos incluídos no ثั. PAC (Plano de Aceleração do Crescimento) do Фं Governo Federal para o Nordeste: saneamento, habitação, recursos hídricos, rodovias e energia elétrica. Partindo do pressuposto de que a dotação de infraestrutura seja uma variável mportante para explicar as disparidades regionais no país, os autores, utilizando um modelo de equilíbrio geral computável e inter-regional, chegam à conclusão de que tais projetos apresentam um claro potencial em termos de aumento da produção e, por essa via, redução das desigualdades regionais. Essas estimativas de redução foram feitas considerando que nenhum investimento desse tipo ocorreria no resto do país. Deve-se levar em conta, no entanto, que os investimentos nas outras regiões mais ricas continuariam ocorrendo, o que significa que os efeitos competitivos e os complementares também estarão sendo ampliados nessas regiões, impedindo a redução das desigualdades. Mas, afinal, qual o poder de atração que a infraestrutura exerce sobre os investimentos privados necessários para promover o desenvolvimento regional? A visão neoclássica tradicional se baseia na noção da perfeita mobilidade de fatores entre regióes. Por ela, o investimento tende a se direcionar para as regióes que oferecem o menor custo de produção, inclusive, custos de transporte. A oferta em uma dada região seria continuamente ajustada pelo comércio com as outras, de forma a manter os custos inter-regionais em permanente equilíbrio. De acordo com essa visão, em um espaço nacional integrado, caso não haja barreiras ao livre curso das forças de mercado, ocorrem fortes pressões para que se estabeleça, ao longo do tempo, uma convergência da renda per capita nos diferentes territórios. As disparidades regionais seriam reduzidas pelo mercado, com o nivelamento de preços, salários e investimentos de capital nos diversos espaços. ${ }^{2}$

Essa visão é criticada por outros autores da economia regional. Por um lado, Perroux (1950) e Myrdal (1957) consideram que não há evidências de que o processo de convergência possa ocorrer de forma natural, mesmo no longo prazo. Para esses autores, caso as forças de mercado sejam livres, haverá uma tendência à divergência, e não à convergência de renda entre regióes, devido aos efeitos de economias de escala e de aglomeração, que tendem a concentrar capital, produção e emprego em regiões inicialmente mais desenvolvidas, levando à perpetuação do desenvolvimento desequilibrado pela atuação do processo circular e cumulativo de crescimento. A provisão de infraestrutura diferenciada seria uma das formas de serem combatidos os desequilíbrios regionais.

Por outro lado, outros autores criticam a visão neoclássica, considerando-a bastante simplista quanto à percepção da natureza do ${ }^{2}$ Ver, por exemplo, Williamson (1965). 
processo de decisão sobre investimentos. Nessa linha, eles chamam a atenção para a necessária relação de complementaridade entre investimento público e privado. Tal relação seria de suma importância para se entender o processo de desenvolvimento regional e para a prescrição de políticas de desenvolvimento. Eles sustentam que as decisões de investimento em uma região são tomadas com base na durabilidade do capital, na natureza sequencial e interdependente das decisões de investimentos em capacidade produtiva, na importância das indivisibilidades dos investimentos regionais e nas disputas pelo fluxo de capitais entre as diversas regiões. Assim, de acordo com essa visão, não é possível postular a perfeita mobilidade dos fatores. O problema, ao se abraçar essa abordagem, porém, é que pouco se sabe sobre o efeito gerador de investimentos privados decorrentes dos vários tipos de infraestrutura. Mais importante, para o caso em tela neste artigo, é que se sabe muito pouco sobre os efeitos das condições pré-existentes em uma dada região e sobre as possibilidades de a infraestrutura atrair novos investimentos (Eberts, 1990). Em outras palavras, não são realizadas analises sobre os efeitos da expansão da infraestrutura nas expectativas dos agentes em relação às potencialidades de determinado território (Martin; Sunley, 1998).

De fato, no painel de trabalhos revisados por Munnel (1992), os resultados das estimativas do impacto dos investimentos em infraestrutura no crescimento econômico diminuem quando a unidade de observação se move do âmbito nacional para os âmbitos estadual e local. Conforme Munnel, ${ }^{3}$ no contexto nacional, a elasticidade do investimento em relação ao produto - que indica quanto $1 \%$ de aumento no investimento provoca de crescimento na economia, - atinge, no máximo, 0,39\% e, no mínimo, 0,34\%. No nível estadual, a elasticidade pode atingir, no máximo, 0,20\% e, no mínimo, 0,15\%. Já no âmbito das áreas metropolitanas, o máximo é de 0,08\% e o mínimo apenas 0,03\%. Ou seja, à medida que o foco geográfico se es-

${ }^{3}$ Ver dados da Tabela 2. treita, o impacto da infraestrutura sobre o crescimento se reduz. A explicação mais direta para esse fenômeno é que os efeitos positivos dos investimentos vazam para áreas mais amplas, reduzindo seus impactos quando o foco é direcionado para espaços territoriais mais reduzidos.

Segundo Eberts (1990), as evidências parecem indicar que, em síntese, o efeito da infraestrutura pública no desenvolvimento regional depende do tipo de investimento e das pré-condições existentes na região. De uma forma geral, nota-se que alguns tipos de infraestrutura geram efeitos significativos, outros não. Pode-se também lembrar os argumentos de Hansen (1965) e Hirschman (1958): para áreas pouco desenvolvidas, criar um tamanho mínimo de urbanização, indispensável para a promoção do desenvolvimento, seria a principal contribuição dos investimentos subsidiados em infraestrutura. No entanto, para essas regiões, o mero provimento de infraestrutura pode não ser suficiente, requerendo outros tipos de investimentos, a exemplo da qualificação da força de trabalho e da urbanização. Nesse tipo de abordagem, para que se possam promover mudanças significativas, investimentos em infraestrutura devem fazer parte de uma clara estratégia de desenvolvimento regional que considere, além do crescimento econômico, a sustentabilidade ambiental e a qualidade de vida dos habitantes da região. Para tanto, a estratégia deve considerar a diversidade econômica, social, política e institucional prevalecente em cada território. Ademais, há de se considerar a natureza do projeto de investimento em infraestrutura em sua capacidade de gerar retornos e externalidades positivas (Barca; Mccann; Rodríguez-Pose, 2012). Essa breve revisão da literatura indica dois pontos que devem ser analisados ao se tentar estimar os efeitos de um projeto de infraestrutura em uma região, além do crescimento econômico. Primeiro, a natureza e a qualidade do projeto, bem como, a sua inserção em um plano de desenvolvimento regional integrado. Segundo, as condições socioeconô- 
micas pré-existentes na região, tendo em vista identificar os fatores que podem potencializar os benefícios do próprio projeto. Esses dois pontos serão analisados nos próximos itens.

\section{O PROJETO DA PONTE SALVA- DOR-ITAPARICA}

Quando da fundação de Salvador, em 1549, a decisão de localizar a cidade próxima à entrada da Baía de Todos os Santos (BTS), pela barra Nordeste, levou em conta razões estratégicas e econômicas. Do ponto de vista estratégico, o sítio escolhido oferecia um porto seguro e protegido de ataques inimigos à capital da colônia, ainda a ser desbravada. Do ponto de vista econômico, o entorno da baía, desde então chamado Recôncavo, continha solo fértil abundante para a cultura da cana-de-açúcar (massapê), principal produto de exportação do país durante todo o período colonial (Simonsen, 2005). Além disso, a produção de açúcar poderia ser escoada por via aquática, utilizando-se as próprias águas abrigadas da grande baía e dos rios que nela desaguam, até o grande porto da capital. Ainda na década de 1950, a via aquática era o principal meio de comunicação de Salvador com o seu Recôncavo e daí até o sertão, tanto para o transporte de carga, como స్ de passageiros. A partir da segunda metade do Фं Século XIX, foram construídas três ferrovias que interligavam a capital ao interior do estado, sendo que uma delas, a Estrada de Ferro de Nazaré, tinha como ponto final o porto de São Roque, perto da foz do rio Paraguaçu, por onde se conectava, por via marítima, a Salvador. ${ }^{4}$

Essa situação começou a mudar com o início do processo de industrialização da Bahia, que foi ancorado na capital do Estado e no seu entorno, na área hoje denominada Região Metropolitana de Salvador (RMS). A تే partir da década de 1950, com a construção da

${ }^{4}$ O livro Baía de Todos os Santos: aspectos humanos, organizado por Soares, Tavares e Pereira (2011) traça um belo e profundo retrato da história e das condições atuais da BTS.
Refinaria Landulpho Alves, em Mataripe, no município de São Francisco do Conde, antigo celeiro de engenhos de açúcar, a via rodoviária foi se expandido até se tornar o principal meio de transporte do Recôncavo e de todo o estado, em processo semelhante ao que ocorreu no país. As vias aquáticas do Recôncavo decaíram velozmente, juntamente com a produção de açúcar, sendo hoje, com exceção do Sistema Ferry Boat, que liga Salvador à Ilha de Itaparica, utilizadas quase exclusivamente para fins recreativos. A movimentação de cargas e passageiros para o interior do estado e outras regiões do país passou a ser feita, em sua quase totalidade, por via rodoviária. Ao mesmo tempo, além da expansão do Porto de Salvador, outros terminais marítimos foram criados no interior da Baía de Todos os Santos (BTS), com o principal objetivo de servir ao comércio exterior.

Como Salvador está localizada na ponta de uma península formada pelas águas da BTS e as oceânicas, a via rodoviária exige que se faça o contorno de boa parte da baía para se atingir o rumo norte, sul ou oeste. Isso significa que a BR 324, no trecho entre Salvador e Feira de Santana, com $100 \mathrm{~km}$ de extensão, é a única via de ligação da RMS, por meio terrestre, com a maioria das outras regiões. Esse trecho rodoviário, além de alongar as distâncias, encontra-se hoje congestionado, e tende a piorar, considerando o poder de atração que exerce sobre atividades produtivas e de povoamento.

Por outro lado, a expansão urbana de Salvador, a partir dos anos 1970, acompanhou sua costa Nordeste, em direção à orla marítima da cidade. Essa expansão invadiu áreas de outros municípios (Lauro de Freitas, Camaçari), fugindo do centro histórico densamente ocupado e, ao mesmo tempo, se aproximando do Polo Industrial de Camaçari, principal distrito industrial do Estado. Essa situação criou um enorme fluxo de trânsito nessa direção que, até hoje, só é atendido pelo transporte sobre rodas, provocando uma saturação das vias, que são constantemente alargadas sem que os engarrafamentos diários desapareçam. 
Nesse contexto, ressurge, em 2010, a ideia de se construir uma ponte entre Salvador e a Ilha de Itaparica, abrindo um novo corredor de trânsito em direção ao oeste e ao sul e, ao mesmo tempo, proporcionando a ocupação urbana de forma mais densa da Ilha. A ponte já havia sido proposta em 1967, por ocasião da elaboração do Plano Diretor do Centro Industrial de Aratu (CIA), localizado às margens da BTS, na direção norte em relação à cidade de Salvador. A proposta do Plano Diretor, coordenado pelo arquiteto Sergio Bernardes, integrava a ponte a um anel viário do Recôncavo, ideia que também foi abarcada pelo presente projeto, embora sem, até agora, muitos detalhes. A Figura 1 situa o projeto da ponte no território em tela.

Figura 1- Situação da Ponte Salvador-Itaparica na BTS
Ilha de Itaparica, promover a integração entre regiões do estado. São três os principais objetivos: eficiência logística, desenvolvimento urbano e desenvolvimento socioeconômico. Em relação à logística, o foco é a eliminação do gargalo da BR 324. Para tanto, além da ponte, prevê-se a realização de investimentos adicionais na infraestrutura viária da região:

- Construção dos acessos viários na Ilha de Itaparica e na cidade de Salvador.

- Redefinição do traçado da BA-001 na Ilha de Itaparica.

- Duplicação da Ponte do Funil, entre a Ilha de Itaparica e o continente, na sua contra costa. - Requalificação da BA-001 e BA-046 até Santo Antônio de Jesus.

- Construção de trecho de rodovia (aproximadamente 58 km) entre Santo Antônio de Jesus e Castro Alves.

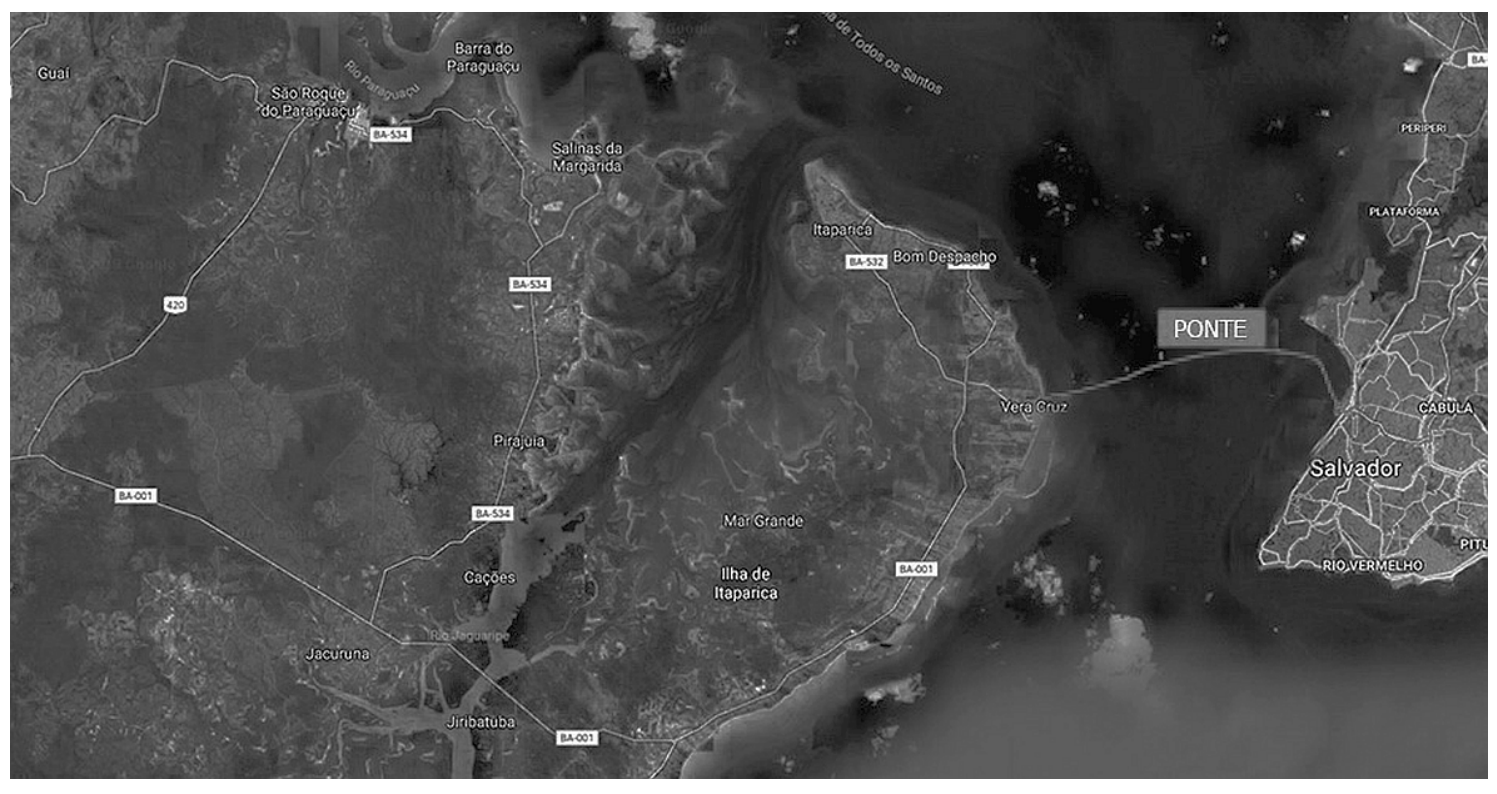

Fonte: Google Maps e INEMA (2018).

- Requalificação da ligação viária entre Castro Alves e a BR-116.

O atual projeto da Ponte Salvador-Itaparica, como parte do Sistema Viário do Oeste (SVO), ${ }^{5}$ tem por propósito, de acordo com as informações oficiais, além de ligar a capital à

${ }^{5}$ Informações detalhadas sobre o projeto podem ser encontradas em PONTE DO DESENVOLVIMENTO < http:// www.pontesalvadorilhadeitaparica.ba.gov.br/>, site que foi usado como principal fonte de informações deste item.

- Novas avenidas em Salvador.

No que se refere ao desenvolvimento urbano, o propósito é abrir uma nova área de expansão para Salvador, em direção à Ilha de Itaparica, que, hoje, tem uma baixa taxa de ocupação: cerca de 60 mil moradores para 146 quilômetros quadrados. Para que esse cresci- 
mento urbano seja ordenado, o projeto prevê algumas providências:

- Revisão dos Planos Diretores de Desenvolvimento Urbano (PDDU) de Itaparica e Vera Cruz.

- Criação de planos urbanísticos municipais e intermunicipais.

- Elaboração do plano de saneamento.

- Análise dos impactos urbanos e de vizinhança.

- Investimentos em infraestrutura básica para a região.

Quanto ao desenvolvimento socioeconômico, de acordo com o projeto, a Ponte e o Sistema Viário do Oeste proporcionarão, por meio da atração de investimentos, o desenvolvimento dos territórios do Baixo Sul e do Recôncavo Sul, que possuem indicadores sociais e econômicos bastante inferiores aos da RMS e do Recôncavo Norte, territórios que absorveram os investimentos decorrentes do processo de industrialização do Estado.

A construção da ponte foi orçada em R\$ 7 bilhões, sem incluir os investimentos complementares. Em 11 de junho de 2016, o Instituto do Meio Ambiente e Recursos Hídricos (INEMA), do governo estadual, emitiu a licença prévia ambiental para a construção do Sistema Viário Oeste (SVO), incluindo a Ponte Salvador-Itaparica. ${ }^{6}$ Porém a crise econômica $\infty$ que se instalou desde 2014 não permitiu que preendimento, mas estabelece uma série de condicionantes que devem ser cumpridas para a obtenção da licença de implantação da obra. modal rodoviário. Estão previstas duas pistas para transporte coletivo, que poderá ser para Veículo Leve sobre Trilhos (VLT) ou Bus Rapid Transit (BRT). Essa modalidade, porém, só seria implantada após a Ponte ser concluída, em outro projeto de investimento que, pelo que vem sendo divulgado, não é prioridade. Dadas essas características, o SVO tende a agravar os problemas de trânsito hoje enfrentados por Salvador, uma vez que a junção da Ponte com a cidade possivelmente se constituirá em novo gargalo, dado o grande fluxo de veículos que atrairá. Deve-se considerar que a Ponte em análise atenderá a uma demanda espalhada por toda a RMS, que hoje utiliza vias que não adentram a capital. Nesse cenário, a qualidade de vida dos habitantes de Salvador seria negativamente afetada pelo aumento das horas perdidas em engarrafamentos.

Ainda em relação à logística, o projeto descartou a alternativa de se construir uma nova saída para Salvador por meio de uma via de contorno da BTS. Essa alternativa, além de ser mais barata e menos impactante na paisagem da baía, ofereceria nova possibilidade para que empreendimentos já existentes nesse contorno pudessem escoar sua produção, reduzindo custos de transporte e logística. Nesse contorno estão situados o Centro Industrial de Aratu (CIA), o Terminal de Madre de Deus (petróleo e derivados), empresas de fertilizantes em torno de Candeias, a Refinaria de Mataripe, empresas industriais em Santo Amaro, o estaleiro em Maragogipe, entre outros. Essa alternativa poderia contemplar também uma via férrea para passageiros e carga, conectando-se com a Ferrovia Centro Atlântica. Com isso, o projeto poderia ser mais facilmente justificável do ponto de vista econômico, uma vez que não estaria destinado, primordialmente, a facilitar a ocupação urbana da Ilha de Itaparica, e sim a aumentar a competitividade de atividades já existentes e, por essa via, atrair novos investimentos. Além disso, não estaria privilegiando apenas o modal rodoviário. ${ }^{7}$

${ }^{7} \mathrm{O}$ arquiteto e professor Paulo Ormindo de Azevedo tem 
Não está bem claro se a Ilha de Itaparica poderá representar um novo vetor de crescimento qualificado para Salvador, desde quando não está identificada a possível demanda por habitações que resultaria da construção da Ponte. A Ilha, historicamente, se constituiu em local de veraneio para habitantes de Salvador. Na década de 1970, com a criação do sistema Ferry Boat e a construção da Ponte do Funil na sua contracosta, ela foi gradualmente submetida a um processo de degradação urbana, pelo fato de não oferecer a infraestrutura básica para o aumento da sua população fixa, veranistas e visitantes. Com isso, sua vocação para o turismo qualificado se perdeu, restando áreas faveladas e sérios problemas urbanos e sociais (educação, saúde, segurança).

Ademais, não está definido como os terrenos vazios mais valorizados serão ocupados. Foi divulgado que esses terrenos seriam desapropriados e entrariam na composição financeira do projeto, ajudando a financiá-lo. Até agora, no entanto, além da elaboração de um Plano Urbano Intermunicipal, ${ }^{8}$ nada foi feito para iniciar um processo de requalificação da Ilha, que pode se tornar em um mero local de passagem de intenso fluxo rodoviário, como muitos outros no país. Caso nossa tradição seja mantida e a Ponte seja construída, os investimentos em infraestrutura urbana e social serão muitas vezes adiados, acelerando-se o processo de degradação da qualidade de vida em um local que poderia se tornar um santuário ecológico bem próximo a Salvador, servido por transporte aquático, com condições de retomar sua vocação para o turismo qualificado. ${ }^{9}$

se destacado como um grande crítico do projeto da Ponte e, ao mesmo tempo, defensor da alternativa do contorno. Seus artigos divulgados na imprensa local podem ser acessados em <http://ruadegentecoletaneaormindo.blogspot. com.br/2013/05/ponte-versus-industria-nautica-e-turismo. html>.

${ }^{8} \mathrm{O}$ Plano Urbano Intermunicipal (PUI) da Ilha de Itaparica pode ser acessado em http://www.pontesalvadorilhadeitaparica.ba.gov.br/estudos/plano-urbano-intermunicipal-pui/

${ }^{9}$ Um paralelo poderia ser feito com o Polo Petroquímico de Camaçari. O projeto original, que foi instalado na década de 1970, previa a criação de infraestrutura urbana e social para fixar os trabalhadores próximos do seu local de trabalho. As indústrias começaram a funcionar sem essa
Essas críticas ao projeto da Ponte Salvador-Itaparica encontram respaldo no trabalho de Flyvbjerg (2009). De acordo com esse autor, em grandes projetos de infraestrutura, as análises de custos e benefícios normalmente subestimam os custos e superestimam os benefícios, levando a ruinosas questões financeiras para os investidores. O autor também chama atenção para o fenômeno do apego dos agentes decisores a uma determinada solução (lock in), deixando de lado a análise de alternativas que podem ser mais promissoras. Nas análises de custos e benefícios tradicionais, os impactos socioambientais geralmente tendem a ser minimizados, gerando problemas que podem levar a sérios conflitos sociais.

Por último, o objetivo de desenvolvimento socioeconômico concentra-se na melhoria dos indicadores dos territórios do Baixo Sul e do Recôncavo Sul, por meio da atração de investimentos que o SVO proporcionará. Não se observa, no entanto, uma visão mais ampla dessa questão, que leve em consideração a dimensão socioambiental, nem se explicita de que forma a infraestrutura de transporte se relaciona com um plano de desenvolvimento regional integrado. Uma concepção em tais bases pode contribuir para o processo de concentração econômica na RMS, uma vez que as vias a serem construídas podem atrair mais investimentos para a Grande Salvador e não para os territórios que não possuem infraestrutura econômica e social. Como foi visto no item anterior, a mera existência de transportes pode não ser suficiente para atrair investimentos, caso não sejam criadas outras formas de gerar externalidades positivas. Ou seja, ao invés de se tornar um vetor de descentralização e distribuição, o SVO pode militar a favor da concentração, que já é bastante elevada no Estado (Teixeira; Guerra; Sousa, 2011), encetando o processo circular e cumulativo de crescimento do qual falava Myrdal (1957).

infraestrutura. O resultado é que a área ente Salvador e o Polo se tornou um problema urbano que até hoje não foi equacionado, fazendo de Salvador uma cidade-dormitório, com a demanda por infraestrutura aumentada sem o correspondente aumento de impostos. 
No próximo item, serão analisadas as pré-condições socioeconômicas existentes nos territórios do Recôncavo Baiano, Baixo Sul, Vale do Jiquiriçá e Região Metropolitana de Salvador, que são aqueles a serem potencialmente impactados pelo SVO e sua ponte.

\section{AS PRÉ-CONDIÇÕES NOS TERRI- TÓRIOS}

Pela Figura 2, pode-se perceber que os possíveis impactos do SVO vão além dos territórios do Recôncavo e do Baixo Sul e, por essa razão, serão aqui prospectados, além desses dois, os territórios do Vale do Jiquiriçá e da Região Metropolitana de Salvador. Serão utilizados dados sobre população, PIB e PIB per capita, emprego e indicadores de desempenho econômico e social. O Quadro 1, a seguir, relaciona os municípios que formam cada um dos quatro territórios.

Figura 2 - Bahia: Territórios de Identidade e área de abrangência dos investimentos considerados (SVO e correlatos)

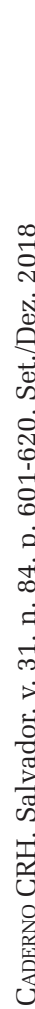

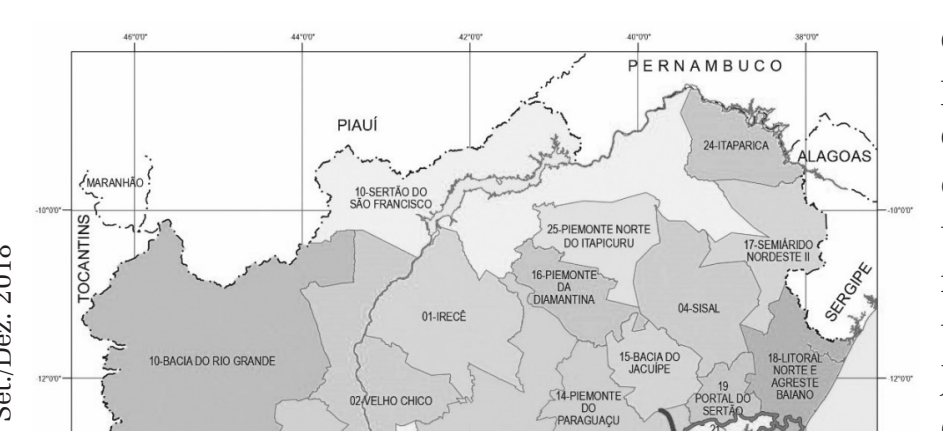

Quadro 1 - Bahia: municípios de Territórios de Identidade selecionados

\begin{tabular}{|c|c|}
\hline $\begin{array}{l}\text { Metropolitana } \\
\text { de Salvador }\end{array}$ & $\begin{array}{l}\text { Camaçari, Candeias, Dias D’Avila, } \\
\text { Itaparica, Lauro de Freitas, Madre de } \\
\text { Deus, Salinas da Margarida, Salvador, } \\
\text { Simões Filho, Vera Cruz }\end{array}$ \\
\hline Recôncavo & $\begin{array}{l}\text { Cabaceiras do Paraguaçu, Cachoeira, } \\
\text { Castro Alves, Conceição do Almeida, } \\
\text { Cruz das Almas, Dom Macedo Costa, } \\
\text { Governador Mangabeira, Maragogipe, } \\
\text { Muniz Ferreira, Muritiba, Nazaré, } \\
\text { Santo Amaro, Santo Antônio de Jesus, } \\
\text { São Felipe, São Félix, São Francisco } \\
\text { do Conde, São Sebastiao do Passé, } \\
\text { Sapeacu, Saubara. }\end{array}$ \\
\hline Baixo Sul & $\begin{array}{l}\text { Aratuípe, Cairu, Camamu, Gandu, } \\
\text { Igrapiúna, Ituberá, Jaguaripe, Nilo } \\
\text { Peçanha, Piraí do Norte, Presidente } \\
\text { Tancredo Neves, Taperoá, Teolândia, } \\
\text { Valença, Wenceslau Guimarães. }\end{array}$ \\
\hline $\begin{array}{l}\text { Vale do } \\
\text { Jiquiriçá }\end{array}$ & $\begin{array}{l}\text { Amargosa, Brejões, Cravolândia, Elísio } \\
\text { Medrado, Irajuba, Iramaia, Itaquara, } \\
\text { Itiruçu, Jaguaquara, Jiquiriçá, Lafaiete } \\
\text { Coutinho, Laje, Lajedo do Tabocal, } \\
\text { Maracás, Milagres, Mutuípe, Nova } \\
\text { Itarana, Planaltino, Santa Inês, São } \\
\text { Miguel das Matas, Ubaíra }\end{array}$ \\
\hline
\end{tabular}

A Tabela 1 apresenta a população dos Territórios de Identidade que estão sendo analisados, bem como o percentual da população de cada um em relação ao Estado e o crescimento em cada um, de 2006 a 2014. Nota-se que as populações da Região Metropolitana de Salvador e do Baixo Sul cresceram acima da média de 8,6\% do Estado, enquanto os dois outros territórios cresceram abaixo dessa média. Chama atenção o crescimento negativo da população do Vale do Jiquiriçá, ${ }^{10}$ indicando a possibilidade da existência de um êxodo desse território pela falta de oportunidades de emprego, uma vez que a relação entre empregos formais e população, em 2006, era de apenas 4,8\%, enquanto, na RMS, atingia 25,1\%, no Recôncavo 10,9\% e no Baixo Sul 6,3\%. Portanto, a RMS continua atraindo novos habitantes, pela oferta de empregos, assim como o Baixo Sul, pelo emprego vinculado ao ${ }^{10}$ É importante observar que não houve alteração dos limi-
tes do território durante o período em estudo. 
Tabela 1 - Bahia: população em Territórios de Identidade selecionados: 2006-2014

\begin{tabular}{l|c|c|c|c|c}
\hline $\begin{array}{l}\text { Territórios de } \\
\text { Identidade }\end{array}$ & $\mathbf{2 0 0 6}$ & $\begin{array}{c}\text { \% da } \\
\text { Bahia }\end{array}$ & $\mathbf{2 0 1 4}$ & $\begin{array}{c}\text { \% da } \\
\text { Bahia }\end{array}$ & $\begin{array}{c}\text { Crescimento } \\
\text { (\%) }\end{array}$ \\
\hline $\begin{array}{l}\text { R. Metropolitana } \\
\text { de Salvador }\end{array}$ & 3.388 .755 & 24,3 & 3.768 .650 & 24,9 & 11,2 \\
\hline Recôncavo & 575.935 & 4,1 & 623.928 & 4,1 & 8,3 \\
\hline Baixo Sul & 316.932 & 2,3 & 364.030 & 2,4 & 14,8 \\
\hline Vale do Jiquiriçá & 335.580 & 2,4 & 333.642 & 2,2 & $-0,6$ \\
\hline Total Bahia & 13.921 .687 & 100,0 & 15.126 .371 & 100 & 8,6 \\
\hline
\end{tabular}

Fonte: Superintendência de Estudos Econômicos e Sociais da Bahia (2016).

crescimento do turismo, uma vez que a relação entre população e empregos, nesse território, cresceu para 8,7\% em 2013 (ver Tabela 3).

\section{PRÉ-CONDIÇÕES ECONÔMICAS}

A Tabela 2 indica o crescimento do PIB per capita nos quatro territórios, em 2008 e 2012 (último ano disponível). Em primeiro lugar, cumpre destacar a alta concentração econômica na RMS, que, em 2012, respondia por $42,7 \%$ do PIB de todo o Estado. Em segundo, observa-se uma grande diferença do PIB per capita entre os territórios: em 2012, o da RMS era 3,15 vezes maior do que o do Vale do Jiquiriçá. Terceiro, observa-se que o território do Recôncavo teve seu PIB per capita reduzido de 2008 para 2012. Isso se deve, fundamentalmente, à queda no PIB de São Francisco do Conde, altamente concentrado na produção da Refinaria de Mataripe, que representava, em 2010, 57\% do PIB de todo o território de identidade do Recôncavo. Considerando que o PIB per capita de todo o Estado, em 2012, foi de R\$
12.858,32, verifica-se que tanto o Baixo Sul como o Vale do Jiquiriçá obtiveram valores abaixo dessa média.

Por fim, as dispersões, medidas pelo desvio padrão do PIB per capita entre os municípios de cada Território de Identidade são elevadas, embora decrescentes em relação às médias de cada um dos anos registrados na Tabela 2, com exceção da RMS. Nesse território, enquanto Candeias e Camaçari, em termos relativos, registraram PIB per capita bastante elevados em 2012 (R \$ 60.583,95 e $\mathrm{R} \$ 49.639,65$, respectivamente), nesse mesmo ano, o de Itaparica atingiu apenas $\mathrm{R} \$ 6.224,78$ e o de Vera Cruz R\$ 7.510,91. No Recôncavo, como já foi mencionado, São Francisco do Conde é o município com o PIB per capita mais alto de todo o estado (R\$ 61.406,66, em 2012), devido à localização da Refinaria de Mataripe. Enquanto isso, o de Muniz Ferreira era de R $\$$ 4.624,91 e o de Cabaceiras do Paraguaçu R\$ $4.788,16$. No Baixo Sul, destacam-se Igrapiúna ( $\mathrm{R} \$ 12.911,43)$ e Cairu ( $\mathrm{R} \$$ 9.383,97), de um lado, e Aratuípe ( $\mathrm{R} \$ 4.692,86)$ e Teolândia ( $\mathrm{R} \$$ $4.836,06)$, de outro. Por último, em todo o Vale do Jiquiriçá prevalece um PIB per capita muito baixo, uma vez que o município que alcança maior valor (Brejões, com R\$ 8.715,63, em 2012) não atinge a média estadual, e apresenta baixa dispersão relativa entre os municípios.

Tabela 2 - Bahia: PIB e PIB per capita em Territórios de Identidade selecionados

\begin{tabular}{|c|c|c|c|c|c|c|c|c|}
\hline \multicolumn{5}{|c|}{2008} & \multicolumn{4}{|c|}{2012} \\
\hline $\begin{array}{ll}\text { Territórios de } \\
\text { Identidade }\end{array}$ & $\begin{array}{c}\text { PIB } \\
\text { (milhões } \\
\text { de reais) } \\
\end{array}$ & $\begin{array}{c}\% \text { PIB } \\
\text { do } \\
\text { Estado }\end{array}$ & $\begin{array}{l}\text { PIB per } \\
\text { capita }\end{array}$ & $\begin{array}{l}\text { Desvio } \\
\text { padrão }\end{array}$ & $\begin{array}{c}\text { PIB } \\
\text { (milhões } \\
\text { de reais) }\end{array}$ & $\begin{array}{c}\% \text { PIB } \\
\text { do } \\
\text { Estado }\end{array}$ & $\begin{array}{l}\text { PIB per } \\
\text { capita }\end{array}$ & $\begin{array}{l}\text { Desvio } \\
\text { padrão }\end{array}$ \\
\hline RMS & 51.790 & 42,7 & 14.112 & 16.296 & 6.8459 & 40,9 & 19.536 & 19.071 \\
\hline Recôncavo & 8.944 & 5,7 & 15.546 & 42.383 & 7.408 & 4,1 & 12.717 & 23.399 \\
\hline Baixo Sul & 2.249 & 1,9 & 6.746 & 13.771 & 3.756 & 2,2 & 11.038 & 12.265 \\
\hline $\begin{array}{ll}\text { Vale } & \text { do } \\
\text { Jiquiriçá } & \end{array}$ & 1.332 & 1,0 & 3.989 & 1.241 & 1.959 & 1,2 & 6.185 & 1.291 \\
\hline
\end{tabular}


Esses números ilustram uma realidade já conhecida, de forte desigualdade de renda no estado da Bahia, confirmada nos quatro territórios que sofrerão mais diretamente os impactos do SVO e sua Ponte. Lembrem-se de que altos PIB per capita são observados nos municípios que abrigam unidades industriais de grande porte, indicando que a distribuição de renda entre seus habitantes é também altamente concentrada. De fato, a Bahia se encontra entre os estados com maior índice de desigualdade de renda, medida pelo Índice de Gini, que, em 2009, atingiu 0,564.

A Tabela 3 mostra a distribuição dos empregos formais por grandes setores de atividades nos quatro territórios, com base na RAIS, Estabelecimentos de 2006 e 2013. ${ }^{11}$ Nota-se, em primeiro lugar, a grande concentração dos empregos na RMS (50,6\%, em 2006, e 48,29\%, em 2013, do total do Estado), maior do que a concentração do PIB, de 40,9\%, em 2012 (Tabela 2), e bem menor do que a concentração da população, de 24,9\%, em 2014 (Tabela 1). Em segundo lugar, a distribuição percentual do emprego entre os grandes setores é diferenciada por território: em 2006, enquanto na RMS os empregos no setor primário respondiam por menos de $0,2 \%$ do total do território; nesse mesmo ano, no Baixo Sul, esse percentual atingia 14\% e 6,4\% no Vale do Jiquiriçá. Já os empregos na indústria de transformação no Recôncavo, também em 2006, abarcavam 16\% do total, enquanto, no Baixo Sul, era de 7,4\%; na RMS, 7,2\%, e, no Vale do Jiquiriça, 5,3\%. Nesse mesmo ano, o setor terciário, incluindo o comércio e outros, somava $83,2 \%$ de todos os empregos formais nos quatro territórios, sendo que na RMS atingia $84 \%$, o maior percentual, e no Recôncavo 73\%, o menor.

A evolução desses números indica que houve uma redução no percentual de pessoas empregadas no setor Primário no total dos quatro territórios (de 1\%, em 2006, para 0,7\%, em 2013) e Terciário - outros (de 67\% para 62\%), enquanto houve aumento no Secundário - outros (de 8\% para 12\%), Secundário - transformação (de 7,8\% para 8,1\%) e comércio (de $15,6 \%$ para $16,7 \%)$.

A Tabela 4 expõe os Índices de Performance Econômica (IPE) dos quatro territórios, conforme é calculada pela SEI, para 2008 e 2010. ${ }^{12}$ Nessa Tabela, são registradas as mé-

Tabela 3 - Bahia: Distribuição do emprego por grandes setores em Territórios de Identidade selecionados - 2006 e 2013

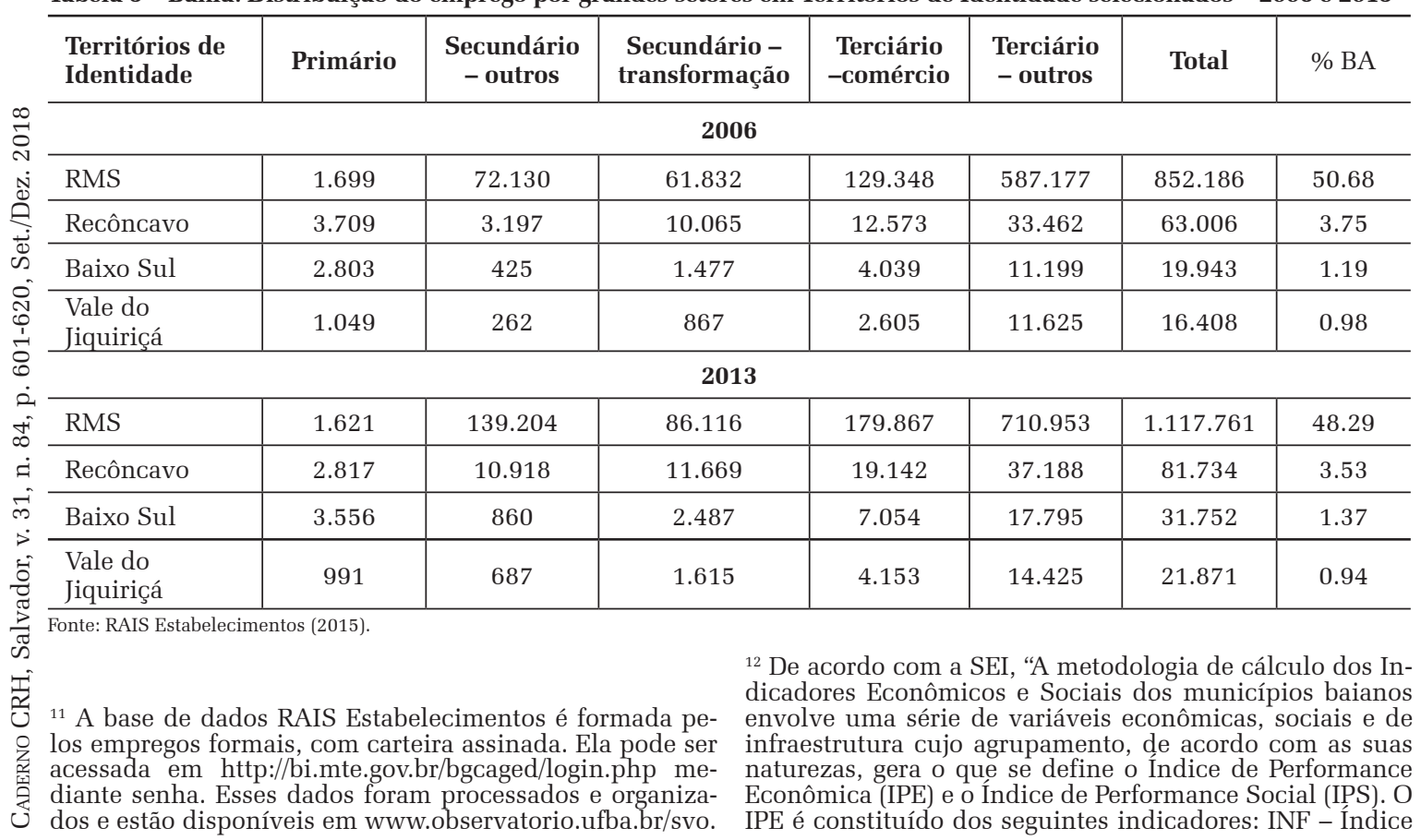


Tabela 4 - Bahia: Índice de Performance Econômica (IPE) de Territórios de Identidade selecionados - 2008 e 2010

\begin{tabular}{l|c|c|c|c}
\hline $\begin{array}{l}\text { Territórios de } \\
\text { Identidade }\end{array}$ & IPE 2008 & $\begin{array}{c}\text { Ranking } \\
\mathbf{2 0 0 8}\end{array}$ & IPE 2010 & $\begin{array}{c}\text { Ranking } \\
\mathbf{2 0 1 0}\end{array}$ \\
\hline RMS & $5.186,60$ & 1 & $5.201,00$ & 1 \\
\hline Recôncavo & $5.031,70$ & 4 & $5.032,85$ & 3 \\
\hline Baixo Sul & $4.985,00$ & 21 & $4.974,64$ & 26 \\
\hline Vale do Jiquiriçá & $4.980,00$ & 25 & $4.980,10$ & 21 \\
\hline Fonte: Observatório de Atividades Econômicas.
\end{tabular}

dias dos índices municipais de cada território, bem como a posição de cada um no ranking dos 26 Territórios de Identidade. ${ }^{13}$ Observa-se que a RMS e o Recôncavo estão bem situados, o mesmo não acontecendo com o Baixo Sul e o Vale do Jiquiriçá. No caso do Recôncavo e do Vale do Jiquiriçá, suas posições no ranking melhoraram de 2008 para 2010, enquanto o Baixo Sul piorou. Pela composição do índice, não surpreende que a RMS esteja em primeiro lugar no ranking. Dos 14 municípios que compõem o Baixo Sul, em 2010, 11 possuíam IPE menor do que 5.000. ${ }^{14}$ Dos 10 municípios da RMS, apenas 1 possuía IPE abaixo de 5.000 naquele mesmo ano. Dos 20 municípios do Recôncavo, 9 possuíam IPE abaixo dessa marca, enquanto, nos 21 do Vale do Jiquiriçá, apenas 3 possuíam IPE superior a 5.000 em 2010.

As pré-condições econômicas dos territórios podem também ser caracterizadas pela identificação de suas aglomerações produtivas. A importância das aglomerações produtivas para o desenvolvimento regional é discutida em Teixeira, Guerra e Sousa (2011). Em

de Infraestrutura; IPM - Índice do Produto Municipal; ICE - Índice de Corrente de Comércio Exterior; IIF - Índice de Independência Fiscal". Ver a metodologia de cálculo em (http://www.sei.ba.gov.br/images/indicadores especiais/ pdf/ipe_ips/ipe_ips_metodologia.pdf).

${ }^{13}$ Após o cálculo desses índices, foi criado mais um Território de Identidade, Costa do Descobrimento, desmembrado do Extremo Sul.

${ }^{14}$ Segundo o método de cálculo da SEI, os municípios foram classificados em ordem decrescente, em cada índice, obtido através da média geométrica dos escores padronizados de cada um deles. O escore padronizado de cada indicador referente aos municípios foi calculado com a adoção da média de 5000. Assim, tem-se uma amplitude de escala onde todos os municípios podem ser diferentes um do outro, evitando-se a superposição dos índices, o que acontece quando do uso de uma escala de amplitude limitada. resumo, a ideia por trás dessa abordagem é que, por meio da melhoria da competitividade de pequenas empresas especializadas setorialmente $\mathrm{e}$ aglomeradas territorialmente, pode-se atingir uma melhor distribuição regional e social de renda, contribuindo para a instalação de um processo de desenvolvimento endógeno sustentado. As políticas de dinamização de aglomerações produtivas são frequentemente interpretadas como uma alternativa inovadora às tradicionais políticas industriais e de desenvolvimento regional.

Teixeira e Araújo (2011) identificaram as aglomerações produtivas de todos os Territórios de Identidade do Estado da Bahia, com base nos dados de empregos constantes da RAIS Estabelecimentos e de acordo com metodologia também nele utilizada. As aglomerações foram classificadas em quatro tipos, conforme resumo apresentado no Quadro 2.

Quadro 2 - Qualificação das aglomerações produtivas

\begin{tabular}{|c|c|}
\hline $\begin{array}{l}\text { Tipo de } \\
\text { aglomeração } \\
\text { produtiva }\end{array}$ & Principal característica \\
\hline $\begin{array}{l}\text { Núcleos de } \\
\text { desenvolvimento } \\
\text { setorial-regional }\end{array}$ & $\begin{array}{l}\text { São de grande importância } \\
\text { econômica para os territórios } \\
\text { onde se localizam e, ao mesmo } \\
\text { tempo, para as atividades que } \\
\text { desenvolvem, considerando o } \\
\text { Estado como um todo. }\end{array}$ \\
\hline Vetores avançados & $\begin{array}{l}\text { São importantes para o } \\
\text { Estado, quando considerada } \\
\text { a participação da atividade } \\
\text { no emprego, mas não são tão } \\
\text { relevantes para os territórios } \\
\text { onde se localizam, por estarem } \\
\text { diluídos em tecidos econômicos } \\
\text { mais diversificados. }\end{array}$ \\
\hline $\begin{array}{l}\text { Vetor de } \\
\text { desenvolvimento } \\
\text { local }\end{array}$ & $\begin{array}{l}\text { São importantes para os } \\
\text { territórios onde se localizam, } \\
\text { mas não são relevantes para as } \\
\text { atividades, quando se considera } \\
\text { o Estado como um todo. }\end{array}$ \\
\hline $\begin{array}{l}\text { Embrião de sistema } \\
\text { local de produção }\end{array}$ & $\begin{array}{l}\text { São constituídos por atividades } \\
\text { que possuem pouca importância } \\
\text { no âmbito do Estado e que } \\
\text { também estão diluídas no tecido } \\
\text { econômico dos territórios. }\end{array}$ \\
\hline
\end{tabular}


Para os quatro Territórios de Identidade em tela, foram identificadas as aglomerações produtivas nos anos de 2006 e 2013, permitindo uma análise da evolução de suas principais atividades. A Tabela 5 relaciona os núcleos de desenvolvimento setorial-regional. Verifica-se que, no período, a metal-mecânica deixou de ser um núcleo de desenvolvimento setorial-regional no Recôncavo, e que o Baixo Sul ganhou duas aglomerações com essas características, indicando um crescimento da importância da sua agricultura para o Estado. A RMS e o Vale do Jiquiriçá não possuíam aglomerações desse tipo.
A Tabela 6 mostra os vetores avançados em 2006 e 2013. Como seria de se esperar, a RMS abriga uma considerável quantidade desse tipo de aglomeração. Das 11 aglomerações, em 2006, com exceção da cadeia automobilística e da química, todas eram vinculadas ao setor terciário e totalizavam 84.263 empregos. Já em 2013, não encontramos aglomerações industriais nesse território. No entanto, as nove aglomerações de 2013 empregavam 140.415 pessoas. O Recôncavo, no período, desenvolveu a indústria de móveis que, em 2013, empregava 800 pessoas nesse território.

A Tabela 7 reTabela 5 - Bahia: núcleos de desenvolvimento setorial-regional 2006 e 2013

\begin{tabular}{l|c|c|c|c|c}
\hline \multicolumn{3}{c}{$\mathbf{2 0 0 6}$} & \multicolumn{3}{c}{$\mathbf{2 0 1 3}$} \\
\hline \multirow{2}{*}{ Território } & Atividade & Empregos & Território & Atividade & Empregos \\
\hline \multirow{2}{*}{ Recôncavo } & $\begin{array}{c}\text { Metal } \\
\text { mecânico }\end{array}$ & 2.492 & Recôncavo & $\begin{array}{c}\text { Cultivo e } \\
\text { preparação } \\
\text { de produtos } \\
\text { do fumo }\end{array}$ & 1.509 \\
\cline { 2 - 6 } & $\begin{array}{c}\text { Cultivo e } \\
\text { preparação } \\
\text { de produtos } \\
\text { do fumo }\end{array}$ & 1.319 & Baixo Sul & $\begin{array}{c}\text { Agricultura } \\
\text { diversificada }\end{array}$ & 1.107 \\
\cline { 4 - 6 } & & & $\begin{array}{c}\text { Cultivo de } \\
\text { cacau }\end{array}$ & 1.212 \\
\hline
\end{tabular}

Fonte: Elaboração própria com base na RAIS Estabelecimentos. laciona os vetores de desenvolvimento local e a Tabela 8 contém os embriões de sistemas locais de produção. Pela análise dessas tabelas, pode-se verificar o baixo dinamismo econômico dos territórios selecionados, principalmente o Baixo Sul e o Vale do

Tabela 6 - Bahia: vetores avançados. 2006 e 2013

\begin{tabular}{|c|c|c|c|c|c|}
\hline \multicolumn{3}{|c|}{2006} & \multicolumn{3}{|c|}{2013} \\
\hline Território & Atividade & Empregos & Território & Atividade & Empregos \\
\hline \multirow{10}{*}{$\begin{array}{l}\text { Metropolitana } \\
\text { de Salvador }\end{array}$} & $\begin{array}{c}\text { Transformação de } \\
\text { plásticos }\end{array}$ & 6.717 & \multirow{9}{*}{$\begin{array}{l}\text { Metropolitana } \\
\text { de Salvador }\end{array}$} & $\begin{array}{c}\text { Atividades de tele } \\
\text { atendimento }\end{array}$ & 13.972 \\
\hline & $\begin{array}{c}\text { Atividades fotográficas } \\
\text { e similares }\end{array}$ & 424 & & $\begin{array}{l}\text { Administração } \\
\text { de edifícios e } \\
\text { condomínios } \\
\end{array}$ & 25.774 \\
\hline & Serviços de TI & 5.590 & & Serviços de TI & 8.927 \\
\hline & $\begin{array}{c}\text { Serviços prestados a } \\
\text { empresas }\end{array}$ & 18.478 & & $\begin{array}{c}\text { Serviços prestados a } \\
\text { empresas }\end{array}$ & 27.792 \\
\hline & $\begin{array}{c}\text { Químicos, } \\
\text { petroquímicos e } \\
\text { fertilizantes }\end{array}$ & 5.585 & & $\begin{array}{c}\text { Serviços de } \\
\text { telecomunicações }\end{array}$ & 13.998 \\
\hline & $\begin{array}{c}\text { Aluguel de máquinas e } \\
\text { equipamentos }\end{array}$ & 3.277 & & $\begin{array}{c}\text { Atividades de } \\
\text { vigilância e segurança } \\
\text { privada } \\
\end{array}$ & 27.973 \\
\hline & $\begin{array}{c}\text { Administração de } \\
\text { edifícios e condomínios }\end{array}$ & 20.422 & & $\begin{array}{l}\text { Locação de mão de } \\
\text { obra temporária }\end{array}$ & 18.836 \\
\hline & $\begin{array}{c}\text { Locação de mão de obra } \\
\text { temporária }\end{array}$ & 12.795 & & Metal-mecânico & 1.910 \\
\hline & \multirow[t]{2}{*}{$\begin{array}{l}\text { Atividades de tele } \\
\text { atendimento }\end{array}$} & \multirow[t]{2}{*}{10.975} & & $\begin{array}{c}\text { Indústria de materiais } \\
\text { de construção }\end{array}$ & 1.233 \\
\hline & & & Recôncavo & Móveis & 800 \\
\hline
\end{tabular}


Tabela 7 - Bahia: vetores de desenvolvimento local 2006 e 2013

\begin{tabular}{|c|c|c|c|c|c|}
\hline \multicolumn{3}{|c|}{2006} & \multicolumn{3}{|c|}{2013} \\
\hline Território & Atividade & Empregos & Território & Atividade & Empregos \\
\hline \multirow{2}{*}{ Baixo Sul } & $\begin{array}{c}\text { Cultivo de } \\
\text { cacau }\end{array}$ & 1010 & \multirow{4}{*}{$\begin{array}{l}\text { Vale do } \\
\text { Jiquiriçá }\end{array}$} & \multirow{2}{*}{$\begin{array}{c}\text { Cultivo e } \\
\text { beneficiamento } \\
\text { de café }\end{array}$} & \multirow{2}{*}{179} \\
\hline & $\begin{array}{c}\text { Agricultura } \\
\text { diversificada }\end{array}$ & 583 & & & \\
\hline \multirow{2}{*}{$\begin{array}{l}\text { Vale do } \\
\text { Jiquiriçá }\end{array}$} & $\begin{array}{c}\text { Cultivo e } \\
\text { beneficiamento } \\
\text { de café }\end{array}$ & 404 & & \multirow{2}{*}{$\begin{array}{c}\text { Criação de } \\
\text { bovinos }\end{array}$} & \multirow[t]{2}{*}{528} \\
\hline & $\begin{array}{c}\text { Criação de } \\
\text { bovinos }\end{array}$ & 388 & & & \\
\hline
\end{tabular}

Fonte: Elaboração própria com base na RAIS Estabelecimentos.

Tabela 8 - Bahia: embriões de sistemas locais de produção 2006 e 2013

\begin{tabular}{|c|c|c|c|c|c|}
\hline \multicolumn{3}{|c|}{2006} & \multicolumn{3}{|c|}{2013} \\
\hline Território & Atividade & Empregos & Território & Atividade & Empregos \\
\hline \multirow{3}{*}{ Baixo Sul } & Indústria alimentícia & 383 & \multirow{3}{*}{ Baixo Sul } & Indústria alimentícia & 844 \\
\hline & Turismo & 583 & & Turismo & 936 \\
\hline & $\begin{array}{c}\text { Atividades de apoio à } \\
\text { agricultura }\end{array}$ & 86 & & $\begin{array}{c}\text { Atividades de apoio à } \\
\text { agricultura }\end{array}$ & 180 \\
\hline \multirow{3}{*}{ Recôncavo } & $\begin{array}{c}\text { Atividades de apoio à } \\
\text { agricultura }\end{array}$ & 147 & \multirow{3}{*}{ Recôncavo } & Indústria alimentícia & 1786 \\
\hline & Indústria alimentícia & 1.055 & & & 1.700 \\
\hline & Móveis & 453 & & Construção civil & 8.856 \\
\hline \multirow{4}{*}{$\begin{array}{l}\text { Vale do } \\
\text { Jiquiriça }\end{array}$} & Indústria alimentícia & 221 & \multirow{4}{*}{$\begin{array}{l}\text { Vale do } \\
\text { Jiquiriça }\end{array}$} & $\begin{array}{c}\text { Atividades de apoio à } \\
\text { agricultura }\end{array}$ & 39 \\
\hline & Cultivo de cacau & 122 & & Cultivo de cacau & 80 \\
\hline & $\begin{array}{c}\text { Indústria de materiais } \\
\text { de construção }\end{array}$ & 191 & & Indústria alimentícia & 693 \\
\hline & Móveis & 320 & & Móveis & 571 \\
\hline
\end{tabular}

Fonte: Elaboração própria com base na RAIS Estabelecimentos.

Jiquiriçá. A grande maioria das aglomerações raterizado, em grande parte, por pessoas com desses territórios está vinculada ao setor pri- baixa renda e pouca escolaridade (Manfredo, mário, que, a princípio, oferece empregos me- 2007).Ou seja, é possível que a facilidade de nos qualificados de baixa remuneração. Em síntese, a análise revela dois territórios mais dinâmicos (RMS e Recôncavo) e dois cujas economias apresentam poucas alternativas de dinamização. Dado esse quadro, não há nada que, a princípio, impeça que o projeto do SVO constitua um vetor de esvaziamento do Baixo Sul e do Vale do Jiquiriçá pela via do processo circular e cumulativo de crescimento.

Casos, como Hortolândia, por exemplo, revelam que a existência de centros urbanos desenvolvidos associados à presença de infraestruturas de deslocamento terminam por transporte proporcionada pela ponte provoque um fluxo migratório maior no sentido dos territórios sem oportunidades de emprego para aqueles com maior dinamismo, o que pode ser reforçado pela capacidade de atração de investimentos dos territórios que possuem infraestrutura econômica e social mais avançada.

\section{PRÉ-CONDIÇÕES SOCIAIS}

Primeiramente, o Índice de Desenvolviimplicar um fluxo migratório de atração, ca- te da realidade social nos Territórios de Iden- 
tidade aqui analisados. ${ }^{15} \mathrm{~A}$ média do IDHM dos dez municípios que compõem a RMS em 2010 (último ano disponível) foi de 0,689, sendo que Salvador atingiu o maior escore $(0,759)$ e Salinas da Margarida o menor $(0,617)$, uma diferença de 18,7\%. Considerando a média, esse território seria considerado como de médio desenvolvimento humano. No Recôncavo, a média dos vinte municípios cai para 0,638, sendo que Santo Antônio de Jesus obteve o maior valor $(0,700)$ e Cabaceiras do Paraguaçu o menor $(0,581)$, com uma diferença de $17 \%$. Também considerando a média, o Recôncavo seria categorizado como de médio desenvolvimento humano. Os quinze municípios do Baixo Sul atingiram a média de 0,576 ,

sendo que Gandu obteve o maior Tabela 9 - Bahia: Índices de Performance Social (IPS) de territórios escore $(0,632)$ e Piraí do Norte o selecionados 2008 e 2010

\begin{tabular}{|c|c|c|c|c|c|}
\hline menor $(0,533)$, com uma diferen & $\begin{array}{l}\text { Territórios de } \\
\text { Identidade }\end{array}$ & IPE 2008 & $\begin{array}{l}\text { Ranking } \\
2008\end{array}$ & IPE 2010 & $\begin{array}{c}\text { Ranking } \\
2010\end{array}$ \\
\hline $\begin{array}{l}\text { ça de } 15,6 \% \text {. Ainda tomando pela } \\
\text { média, esse território seria consi }\end{array}$ & RMS & $5.145,30$ & 1 & $5.134,60$ & 1 \\
\hline derado de baixo desenvolvimentc & Recôncavo & $5.026,95$ & 4 & $5.030,75$ & 3 \\
\hline humano. Por último, a média dos & Baixo Sul & $4.992,86$ & 10 & $4.994,57$ & 14 \\
\hline nte e um municípios do Vale & Vale d & $4.991,86$ & 13 & $4.997,33$ & 10 \\
\hline
\end{tabular}

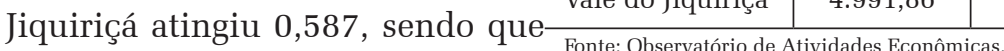

Amargosa obteve o maior valor

$(0,625)$ e Nova Itarana o menor $(0,524)$, uma diferença de $15,5 \%$. Pela média, o Vale do Jiquiriçá seria classificado como de baixo de$\infty$ senvolvimento humano. Portanto, a julgar pelo 亏ें IDHM, a realidade social nos quatro territórios ¿ não pode ser considerada auspiciosa. Pelo con-

†્ 15 "O Índice de Desenvolvimento Humano Municipal ¿ (IDHM) é uma medida composta de indicadores de três - dimensões do desenvolvimento humano: longevidade,

$\vec{m}$ educação e renda. O índice varia de 0 a 1 . Quanto mais

$>$ próximo de 1, maior o desenvolvimento humano. O IDHM

î brasileiro segue as mesmas três dimensões do IDH Global

- longevidade, educação e renda -, mas vai além: adequa

2 a metodologia global ao contexto brasileiro e à disponibili-

Tึ dade de indicadores nacionais. Embora meçam os mesmos

f fenômenos, os indicadores levados em conta no IDHM são

I mais adequados para avaliar o desenvolvimento dos mu-

U nicípios brasileiros." O desenvolvimento municipal pode

ser: muito baixo, de 0 a 0,499 ; baixo de 0,5 a 0,599 ; médio de 0,6 a 0,699 ; alto de 0,7 a 0,799 ; e muito alto acima de 0,8. (PNUD, 2016). Os dados do IDHM para todos os municípios brasileiros podem ser obtidos em IBGE Cidades@.
A Tabela 9 exibe os Índices de Performance Social (IPS) dos quatro territórios ${ }^{16}$, calculados pela média dos índices de cada município. Verifica-se uma situação semelhante ao do IPE, com a diferença que o Baixo Sul e o Vale do Jiquiriçá estão mais bem ranqueados no índice social do que no econômico. Porém o Baixo Sul foi rebaixado no ranking, de 2008 para 2010, enquanto o Vale de Jiquiriçá ascendeu. Enquanto todos os 10 municípios da RMS alcançaram, em 2010, IPS acima de 5000, ${ }^{17}$ dos 20 do Recôncavo, apenas 6 obtiveram tal escore. Já dos 14 do Baixo Sul, 8 ficaram abaixo desse nível e dos 21 do Vale do Jiquiriçá, apenas 10 superaram o nível de 5000 em 2010. 
Francisco Lima Cruz, Sílvio Vanderlei Araújo Sousa

Tabela 10 - Bahia: matrículas e estabelecimentos de educação profissional nos Territórios de Identidade em 2010 e 2012

\begin{tabular}{l|c|c|c|c|c|c}
\hline \multirow{2}{*}{ Territórios } & \multicolumn{2}{|c|}{$\mathbf{2 0 1 0}$} & \multicolumn{2}{c}{$\mathbf{2 0 1 2}$} \\
\cline { 2 - 7 } & Matrículas & $\begin{array}{c}\text { Total de } \\
\text { estabelecimentos }\end{array}$ & $\begin{array}{c}\text { Matrículas } \\
\text { por 1000 } \\
\text { habitantes }\end{array}$ & Matrículas & $\begin{array}{c}\text { Total de } \\
\text { estabelecimentos }\end{array}$ & $\begin{array}{c}\text { Matrículas } \\
\text { por 1000 } \\
\text { habitantes }\end{array}$ \\
\hline RMS & 15875 & 67 & 4,6 & 23703 & 92 & 6,76 \\
\hline Recôncavo & 1747 & 13 & 3,1 & 3013 & 24 & 5,25 \\
\hline Baixo Sul & 1412 & 11 & 4,1 & 2720 & 17 & 7,99 \\
\hline $\begin{array}{l}\text { Vale do } \\
\text { Jiquiriça }\end{array}$ & 952 & 7 & 3 & 1419 & 7 & 4,48 \\
\hline Fonte: Observatório de Atividades Econômicas.
\end{tabular}

qualquer forma, os números não parecem indicar que a oferta de pessoal qualificado tecnicamente, mesmo que em nível médio, possa representar fator de atração de investimentos nos territórios aqui considerados.

Em resumo, os números mostram quatro territórios bastante diferenciados em termos de atividades econômicas, geração de empregos formais e situação social. A diversidade produtiva em cada território dificulta ainda a introdução de projetos estruturantes de interligação de cadeias produtivas e torna mais complexa uma solução uniforme de desenvolvimento via indústria. Uma oportunidade poderia se materializar pelo fortalecimento da indústria alimentícia, que se mostra como embrião de sistema local de produção no Baixo Sul, no Vale do Jiquiriça e no Recôncavo (Tabela 8). Todavia o esforço de desenvolvimento desse setor carece de políticas setoriais complementares. Seria necessário, assim, um diagnóstico do setor de alimentos em seus respectivos territórios de forma a se estudar o grau de especialização do trabalho empregado, a intensidade de capital demandada e o potencial de expansão por conta do aproveitamento das sinergias com o projeto SVO.

Dado esse quadro, não parece possível antever como um projeto de infraestrutura contribuirá para reduzir as desigualdades regionais. Pelo contrário, é possível que o poder de atração dos territórios mais bem situados e que apresentam externalidades relativamente positivas ajude a esvaziar economicamente aqueles que estão próximos e oferecem menores oportu- nidades de investimentos e empregos, embora não se possa de antemão afirmar que essa tendência será predominante. A questão é que o projeto apresentado pelo governo também não permite concluir que a tendência oposta prevalecerá, embora o desenvolvimento dos territórios mais pobres seja um dos seus objetivos.

\section{CONCLUSÕES}

Após a "descoberta" do Brasil por Cabral, em 1501, o rei D. Manoel decidiu explorar as novas terras mandando uma esquadra comandada por Gonçalo Coelho que, em $1^{\circ}$ de novembro, dia de "todos os santos", adentrou o "golfão" que recebeu o nome do santo do dia. Américo Vespúcio, agregado à tripulação, foi o grande divulgador da viagem e de suas descobertas, vindo a receber diversas honrarias, inclusive o nome do novo continente.

Mesmo com toda a exploração econômica que houve em seu entorno desde a primeira metade do século XVI, a Baía de Todos os Santos manteve suas condições ambientais, a sua paisagem e a qualidade das suas águas razoavelmente preservadas. As características geográficas da Baía e seu Recôncavo em muito contribuíram para tal. O padrão de ocupação produtiva e humana, no entanto, também contribuíram para que esse pequeno mar mediterrâneo fosse conservado, principalmente quanto à sua admirada e cantada paisagem. Em nome do desenvolvimento, lança-se o projeto de uma ponte que irá alterar substancialmente 
a paisagem da Baía de Todos os Santos. Um artefato de ferro e concreto, projetado segundo o padrão estético vigente nos dias de hoje em tais empreendimentos, será alçado sobre as águas da baia, na sua parte mais visível do ponto de vista da cidade de Salvador.

Este artigo objetivou analisar o projeto SVO à luz das discussões sobre a relação entre infraestrutura e crescimento econômico, assim como daquelas que ampliam o foco para incluir questões pertinentes ao desenvolvimento em uma perspectiva socioambiental. Orientado pela revisão da literatura que adota esse enfoque mais amplo, este trabalho analisou as principais características do referido projeto, nas suas dimensões da logística e do desenvolvimento, com base nas publicações oficias, e ainda avaliou as pré-condições econômicas e sociais presentes nos quatro Territórios de Identidade que sofrerão mais diretamente seus impactos (RMS, Recôncavo, Baixo Sul e Vale do Jiquiriçá). Tais condições, de acordo com a revisão da literatura, são consideradas fundamentais para que se atinjam objetivos de desenvolvimento regional com sustentabilidade.

Em relação à dimensão logística do projeto, foi questionada sua opção de priorizar o modal rodoviário, em um momento em que, em outros países, procuram-se alternativas que reduzam os impactos negativos do transporte sobre rodas. Questionou-se, também, o abandono de outro projeto que percorreria o contorno da baía, integrando as atividades econômicas já existentes no Recôncavo, oferecendo possibilidades de escoamento da produção e de integração regional, utilizando, além do $\therefore$ modal rodoviário, o transporte sobre trilhos. E $\infty$ que essa área possa adensar seu tecido urbano de forma qualificada. A mera passagem de uma rodovia em um ambiente ainda relativamente preservado tende a criar as condições para o crescimento de concentrações populacionais sub-humanas e para sua degradação.

Do ponto de vista regional, foram aqui analisadas as pré-condições existentes nos quatro territórios que poderiam potencializar os investimentos anunciados pelo governo. A análise revela uma situação já deveras conhecida sobre a realidade baiana: alta concentração econômica, de renda e da infraestrutura social. Dado esse quadro e considerando que os investimentos em infraestrutura urbana e social não estão sendo encarados como prioritários, não seria possível postular que o projeto do Sistema Viário do Oeste, com sua Ponte, poderá contribuir, de forma significativa, para mitigar o quadro de desigualdade prevalecente e para promover o desenvolvimento de territórios para além de um mero crescimento que, ademais, não é possível precisamente quantificar.

O projeto da Ponte Salvador-Itaparica se constitui em um caso exemplar para que se discutam, com mais profundidade, os projetos de investimentos em infraestrutura no país. Estimativas acerca dos efeitos sobre o crescimento econômico proporcionado por tais projetos, como demonstra a literatura aqui revisada, devem ser questionadas, uma vez que elas se revelam imprecisas e variáveis. Ademais, os imperativos da sustentabilidade socioambiental não podem ser vistos como obstáculos que podem ser superados apenas por investimentos mitigadores e que não miram os efeitos em longo prazo. Considerar e analisar esses fatores são medidas fundamentais para que projetos de infraestrutura possam ser integrados a estratégias de desenvolvimento regional, o que, como foi visto, constitui uma condição indispensável para que eles possam proporcionar consistentes benefícios à sociedade.

Recebido para publicação em 24 de agosto de 2016 Aceito em 05 de setembro de 2018 


\section{REFERÊNCIAS}

ANSAR, A. et al. Does infrastructure investment lead to economic growth or economic fragility? Evidence from China. Oxford Review of Economic Policy, United Kingdom, v.32, n.3, 2016

ASCHAUER, D. Is Public Expenditure Productive? Journal of Monetary Economics, v. 23, n. 2, March 1989.

BARCA, F.; McCANN, P.; RODRÍGUEZ-POSE, A. the case for regional development intervention: place-based versus place-neutral approaches. Journal of Regional Science, [s.l], v. 52, n. 1, p. 134-152, 2012.

BENITEZ, R. A infraestrutura, sua relação com a produtividade total dos fatores e seu reflexo sobre o produto regional. Planejamento e Políticas Públicas, Brasília, n. 19, jun. 1999.

CONSELHO ESTADUAL DE DESENVOLVIMENTO TERRITORIAL (CEDETER). Disponível em http:// www.seplan.ba.gov.br/modules/conteudo/conteudo. php?conteudo=18 Acesso em: 22. 08. 2016.

DOMINGUES, E.; VIANA, F.; OLIVEIRA, H. Investimentos em infraestrutura no Nordeste: projeções de impacto e perspectivas de desenvolvimento. Belo Horizonte: UFMG/ Cedeplar, 2007.

EBERTS, R. Public Infrastructure and Regional Economic Development. 1990. Disponível em http://clevelandfed. org/research/review/. Acesso em: 15.08.2016

FERREIRA, P. Investimento em infraestrutura no Brasil: fatos estilizados e relações de longo prazo. Pesquisa e Planejamento Econômico, Rio de Janeiro, v. 26, n. 2, p. 231-252, 1996.

FLYVBJERG, B. Survival of the un-fittest: why the worst infrastructure gets built -- and what we can do about it. Oxford Review of Economic Policy, United Kingdom, v. 25 , n. 3, 2009 .

HANSEN, M. Unbalanced growth and regional development. Western Economic Journal, Califórnia, v. 4, 1965.

HIRSCHMAN, A. O. The Strategy of Economic Development. New Haven: Yale University Press, 1958.

INEMA. Relatório de impacto ambiental. 2018. Disponível em http://www.inema.ba.gov.br/wp-content/files/RIMA PONTE_SSA_ITAP_EBOOK2.pdf. Acesso em: 16.10.2018.

INSTITUTO BRASILEIRO DE GEOGRAFIA E ESTATISTICA (IBGE). 2016. Séries históricas e estatísticas. Disponível em http://seriesestatisticas.ibge.gov.br/default. aspx. Acesso em: 05. 04. 2016.

INSTITUTO, BRASILEIRO DE GEOGRAFIA E ESTATÍSTICA (IBGE). 2016. Cidades@. Disponívelem: http://www.cidades.ibge.gov.br/xtras/ uf.php?lang $=\& \operatorname{coduf}=29 \&$ search $=$ bahia . Acesso em: 21.08. 2016

MANFREDO, M. T. Desigualdades e produção do espaço urbano: o caso de Hortolândia na região metropolitana de Campinas. 2007. Dissertação (Mestrado) Universidade Estadual de Campinas.

MARTIN, R.; SUNLEY, P. Slow convergence? the new endogenous growth theory and regional development. Economic Geography, United States, v. 74, n. 3, p. 201-227, July 1998.

MUNNEL, A. Infrastructure investment and economic growth. Journal of Economic Perspectives, Nashville, v. 6, n. 4, p. 1992

MYRDAL, G. Teoria econômica e regiões subdesenvolvidas. Rio de Janeiro: Saga,1957.

PERROUX, F. Economic space: theory and applications.
Quarterly Journal of Economics, Cambridge, v. 64, p. 9-104, 1950.

OBSERVATÓRIO DE ATIVIDADES ECONÔMICAS. 2016. Disponível em: http://www.observatorio.ufba.br/svo. Acesso em: 05. 07. 2016.

PLANO URBANO INTERMUNICIPAL (PUI) DA ILHA DE ITAPARICA. Disponível em http://www. pontesalvadorilhadeitaparica.ba.gov.br/estudos/planourbano-intermunicipal-pui/. Acesso em: 15. 07. 2016.

PONTE DO DESENVOLVIMENTO. Disponível em http:// www.pontesalvadorilhadeitaparica.ba.gov.br/. Acesso em: 15. 06. 2016.

PNUD. Disponível em http://www.pnud.org br/IDH/IDHM.aspx?indiceAccordion=0\&li=li_IDHM. Acesso em: 22. 08. 2016.

SEI. Estatísticas dos municípios baianos. 2014. Disponível em http://www.sei.ba.gov.br/index.php?option=com content\&view $=$ article\&id $=2441 \&$ Itemid $=284$. Acesso em: 16.10. 2018.

SIMONSEN, R. História Econômica do Brasil 1500-1820. Brasília: Senado Federal, Conselho Editorial, 2005.

SOARES, C. A. C.; TAVARES, F.; PEREIRA, C. (Orgs.) Baía de Todos os Santos: aspectos humanos. Salvador: EDUFBA, 2011.

SUPERINTENDÊNCIA DE ESTUDOS ECONÔMICOS E SOCIAIS DA BAHIA. 2016. Bahia em Números. Disponível em: http://www.sei.ba.gov.br/index.php?option=com content\&view $=$ article\&id $=148 \&$ Itemid $=235$. Acesso em: 04. 07. 2016.

SUPERINTENDÊNCIA DE ESTUDOS ECONÔMICOS E SOCIAIS DA BAHIA. http://www.sei.ba.gov.br/images/ indicadores especiais/pdf/ipe ips/ipe ips metodologia. pdf. Acesso em: 18. 07. 2016.

SUZIGAN, W. et al. Clusters ou sistemas locais de produção: mapeamento, tipologia e sugestões de políticas. Revista de Economia Política [s.1], v. 24, n. 4, 2004.

TEIXEIRA, F. GUERRA, O. E; SOUSA, S. V. A. Limites para uma dinâmica endógena na economia baiana. Bahia Análise e Dados, Salvador, v. 21, n. 2, p. 23-46, abr./jun. 2011.

WILLIAMSON, J. Regional inequality and the process of National development: a description of the patterns. Economic Development and Cultural Change, Chicago, v.13, n. 4, p.1-84, 1965. Retrieved from http://www.jstor. org/stable/1152097. Acesss en: 02. 07. 2016. 


\section{INFRASTRUCTURE AND DEVELOPMENT: what can be expected from the bridge Salvador- Itaparica? Bahia-Brazil}

\author{
Francisco Lima Cruz Teixeira \\ Sílvio Vanderlei Araújo Sousa
}

This paper aims at analyzing the design of the Road System of the West (SVO), which include the construction of Salvador-Itaparica Bridge, in the light of the discussions on the relationship between infrastructure and economic growth, as well as those that expand the focus to include issues relevant to development. This review was used to assess the project and to examine the social and economic preconditions that are present in four Territories of Identity that will suffer more directly their impacts (Metropolitana de Salvador, Recôncavo, Baixo Sul and Vale do Jiquiriçá). The analysis of the data and information does not allow us to postulate that the project of the Road System of the West and its Bridge could contribute significantly to mitigate the significant inequality and promote the endogenous and sustainable development of the territories.The approach used in this analysis, by rejecting the traditional economic view, extends the discussion of the relationship between investments in infrastructure and regional development using evidences from this case study.

KEYwORDS: Infrastructure. Development. Territories of identity. Productive Settlements. Regional Policies

\section{INFRASTRUCTURE ET DÉVELOPPEMENT: que peut-on attendre du pont Salvador-Itaparica? Bahia-Brésil}

Francisco Lima Cruz Teixeira Sílvio Vanderlei Araújo Sousa

Cet article vise à analyser la conception du Réseau Routier dans l'Ouest (SVO), qui comprennent la construction du pont Sauveur-Itaparica, à la lumière des discussions sur la relation entre l'infrastructure et la croissance économique, mais aussi ceux qui élargissent la portée aux questions relatives au développement. Cet examen a été utilisé pour évaluer le projet et d'examiner le social et les conditions économiques sont présentes dans quatre territoires de l'identité qui souffrira plus directement leurs impacts (Metropolitana de Salvador, Recôncavo, Baixo Sul et la Vale do Jiquiriçá). L’analyse des données ne nous permet pas de postuler que le projet du Réseau Routier de l'Ouest et son pont pourrait contribuer significativement à atténuer le cadre de l'inégalité qui prévaut et promouvoir le développement endogène et durable des territoires.Lapproche utilisée dans cette analyse, en rejetant la vision économique traditionnelle, élargit la discussion sur la relation entre les investissements dans les infrastructures et le développement régional, à l'aide de la preuve de cette étude de cas.

Mots CLÉs: Infrastructure. Développement. Territoires de l'identité. Agglomérations productifs. Politiques régionales. Universidade Federal da Bahia. Membro permanente do seu Núcleo de Pós-Graduação em Administração (NPGA). Tem experiência na área de Gestão e Política de Ciência e Tecnologia, trabalhando principalmente nos seguintes temas: tecnologia, inovação, competitividade, indústria, planejamento e desenvolvimento tecnológico. Atualmente trabalha com temas relacionados à política regional e, na linha da inovação, no desenvolvimento de jogos educacionais nas áreas de inovação, estratégia e políticas públicas. Autor do artigo: Desigualdade, emprego e aglomerações produtivas: análise da dinâmica dos Territórios de Identidade da Bahia. Bahia Análise \& Dados, v. 26, p. 9, 2016.

Sílvio Vanderlei Araújo Sousa - Mestre e Doutor em Administração pelo Núcleo de Pós-Graduação em Administração da UFBA. Autor do artigo: Desigualdade, emprego e aglomerações produtivas: análise da dinâmica dos Territórios de Identidade da Bahia. Bahia Análise \& Dados, v. 26, p. 9, 2016. 